\title{
Carotid artery stenosis is related to blood glucose level in an elderly Caucasian population: the Hoorn Study
}

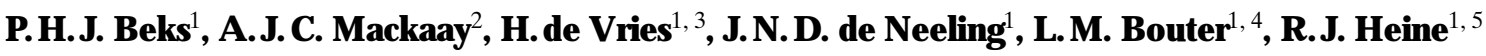 \\ ${ }^{1}$ Institute for Research in Extramural Medicine, Vrije Universiteit, Amsterdam, The Netherlands \\ ${ }^{2}$ Department of Vascular Surgery, Academic Hospital of the Vrije Universiteit, Amsterdam, The Netherlands \\ ${ }^{3}$ Department of General Practice, Nursing Home Medicine and Social Medicine, Vrije Universiteit, Amsterdam, The Netherlands \\ ${ }^{4}$ Department of Epidemiology and Biostatistics, Vrije Universiteit, Amsterdam, The Netherlands \\ ${ }^{5}$ Department of Internal Medicine, Academic Hospital of the Vrije Universiteit, Amsterdam, The Netherlands
}

Summary Cross-sectional associations between carotid artery stenosis (CAS) on the one hand, and parameters of glycaemia and specific insulin levels on the other, were investigated in an age, sex, and glucose tolerance stratified random sample from a 50 74-year-old Caucasian population. Subjects treated with insulin or oral hypoglycaemic agents were classified as having known diabetes mellitus (KDM) $(n=66)$. Using two oral glucose tolerance tests, and based on the World Health Organisation criteria, all other participants were classified as having a normal (NGT) $(n=287)$, an impaired (IGT) $(n=169)$ or a diabetic $(N D M)(n=106)$ glucose tolerance. CAS was defined haemodynamically using duplex scanning. The crude prevalences of only moderate (16$49 \%$ ) CAS were $6.6 \%, 7.1 \%, 5.7 \%$ and $12.1 \%$ in NGT, IGT, NDM and KDM subjects, respectively. For any severe $(\geq 50 \%)$ CAS, crude prevalences were $2.8 \%, 4.7 \%, 9.4 \%$ and $7.6 \%$. The prevalence of any severe CAS was higher in NDM $(p<0.01)$ and KDM subjects $(p=0.07)$ than in NGT subjects. The prevalence of a history of stroke or transient ischaemic attack was $1.7 \%, 1.8 \%, 2.8 \%$ and $1.5 \%$ in NGT, IGT, NDM and KDM, respectively. In univariate logistic regression analysis, $\mathrm{HbA}_{1 \mathrm{c}}$, serum fructosamine, fasting and 2-h post-load glucose were significantly associated with any severe CAS. In multivariate analyses controlling for other risk factors, only $\mathrm{HbA}_{1 \mathrm{c}}$ and 2-h post-load plasma glucose remained significantly associated (odds ratios: 1.29 per $\%$ and 1.09 per $\mathrm{mmol} / \mathrm{l}$, respectively) in separate models. No association could be shown between either fasting or 2-h post-load specific insulin and any severe CAS in either univariate or multivariate analyses. In conclusion, $\mathrm{HbA}_{1 \mathrm{c}}$ and 2-h post-load plasma glucose are independently associated with any severe CAS, whereas specific insulin is not. [Diabetologia (1997) 40: 290-298]

Keywords Non-insulin-dependent diabetes mellitus, impaired glucose tolerance, specific insulin, carotid artery stenosis, epidemiology, population-based survey, Caucasians.
Received: 2 February 1996 and in final revised form: 22 November 1996

Corresponding author: Dr. P. J. Beks, Institute for Research in Extramural Medicine, Vrije Universiteit, Van der Boechorststraat 7, NL-1081 BT Amsterdam, The Netherlands

A bbreviations: CAS, Carotid artery stenosis; NGT, normal glucose tolerance; IGT, impaired glucose tolerance; NDM, newly diagnosed diabetes mellitus; KDM, known diabetes mellitus ( = using oral hypoglycaemic agents or insulin); TIA, transient ischaemic attack; NIDDM, non-insulin-dependent diabetes mellitus; OGTT, oral glucose tolerance test; WHO, World Health Organisation; BMI, body mass index; WHR, waist/ hip-ratio; OR, odds ratio; $95 \%$ CI, $95 \%$ confidence interval.
The prevalence of atherosclerotic vascular disease, manifesting as cardiovascular, cerebrovascular or peripheral arterial disease, is known to be markedly increased in diabetic subjects compared to non-diabetic subjects [1-4]. Symptoms of cerebral ischaemia and infarction have been associated with the presence of severe atherosclerotic carotid artery disease [4-9].

Carotid atherosclerosis has been investigated by means of autopsy, angiography, clinical symptoms and non-invasive ultrasound techniques. Epidemiological studies focused either on the prevalence of carotid artery stenosis (CAS) in symptomatic subjects $[4-6,8,9]$, or in asymptomatic subjects [10-17], 
irrespective of blood glucose level. In only a few studies, was the prevalence of CAS determined in subjects with non-insulin-dependent diabetes mellitus (NIDDM) $[18,19]$. To date, very few studies have included the total range of blood glucose level and reported its association with CAS in a population-based sample.

To study asymptomatic carotid artery disease, combined echo-Doppler (duplex) examination has been used in many epidemiological and clinical studies [4-19]. In the Hoorn Study, the evaluation of the duplex flow velocity curves was chosen as the non-invasive test to diagnose CAS, as it is easily and quickly performed without discomfort for the participant and can accurately be scored on-line. The Hoorn Study took place from 1989 to 1992 . It was a populationbased cross-sectional survey to determine the prevalence of abnormal glucose tolerance, its determinants, and its related disorders in an elderly Dutch Caucasian population [20-23]. In contrast to methods used in all other population-based studies, glucose tolerance was evaluated with two oral glucose tolerance tests (OGTT) to optimize the diagnostic precision, and insulin levels were measured with a specific insulin assay.

The aims of this study were to determine: 1) the prevalence of CAS in an elderly Caucasian population; 2) the association of CAS with various parameters of blood glucose level and specific insulin levels; and 3 ) the eventual confounding of these associations by other cardiovascular risk factors.

\section{Subjects and methods}

Subjects. All study participants were involved in the Hoorn Study, a cross-sectional survey on disturbances of glucose tolerance and diabetes-related disorders in a general Caucasian population. For this study, a random sample of 50-74-year-old subjects was taken from the population register of the town of Hoorn (59000 inhabitants) in the Netherlands. Of the 3553 subjects invited for the study, $2540(71.5 \%)$ participated, of whom 56 were excluded from analysis and further study because they were non-Caucasian. Thus, the final Hoorn Study cohort consisted of 2484 subjects. Information on age, sex, body height, weight, history of diabetes, treatment for hypertension and cardiovascular complaints was obtained by interview from virtually all non-participants (93\%). The non-participants were only slightly, but significantly older (63.1 vs 61.7 years), taller (171 vs $169 \mathrm{~cm})$, lighter (73.1 vs $75.5 \mathrm{~kg})$, and less often had a family history of diabetes (20 vs $27 \%$ ). They did not differ significantly from our study population with respect to sex, self-reported diabetes, treatment for hypertension and cardiovascular symptoms.

The sampling procedure has already been described in detail [20]. Briefly, all cohort members not treated with oral hypoglycaemic agents or insulin underwent a 75-g OGTT, according to World Health Organisation (WHO) recommendations [24] (phase 1). All cohort members with a 2-h post-load plasma glucose level $11.1 \mathrm{mmol} / \mathrm{l}$ or more $(n=122)$, and age and sex-stratified random samples from subjects with a 2-h post-load glucose level $7.5 \mathrm{mmol} / \mathrm{l}$ or more and less than $11.1 \mathrm{mmol} / \mathrm{l}(\mathrm{n}=254$; mean sample fraction $81 \%)$, as well as from those with a 2-h post-load glucose level less than $7.5 \mathrm{mmol} / \mathrm{l}(\mathrm{n}=256$; mean sample fraction $13 \%)$ were invited for a second OGTT (phase 2) and a study of diabetes-related disorders (phase 3). Sample fractions were chosen in such a way that approximately equal numbers of participants in each age, sex, and glucose tolerance stratum would be obtained. Cohort members treated with oral hypoglycaemic agents or insulin $(n=76)$ only had their fasting plasma glucose measured once, and were all asked to participate in the diabetes-related disorder study (phase 3). Thus, a total of 708 subjects were invited for the assessment of CAS.

The Hoorn Study was approved by the ethical review committee of the Academic Hospital of the Vrije Universiteit and informed consent was obtained from all participants.

Non-invasive assessment of CAS. Ultrasonography of the carotid arteries was performed using a colour Duplex scanner (Acuson 128, Mountain View, Calif., USA). Haemodynamic stenosis of the carotid arteries was assessed by using a 7.5$\mathrm{MHz}$ linear transducer in combination with a $5-\mathrm{MHz}$ pulsed doppler. The results were registered by two experienced vascular technicians under the supervision of a vascular surgeon (A.M.). The final interpretation of the doppler flow velocity profiles was made according to standard criteria [25-27] by one vascular surgeon (A.M.) blinded for the glucose tolerance status and the history of stroke or transient ischaemic attack (TIA). Recordings were taken from the proximal and distal common, the external, and also the proximal and distal internal carotid artery on both sides. Recording started after a 15min resting period in a supine position (room temperature $23^{\circ} \mathrm{C}$ ).

Each carotid branch was classified as having no or minimal stenosis $(0-15 \%$ diameter reduction defined as a systolic peak flow velocity $<1.25 \mathrm{~m} / \mathrm{s}$ and no spectral broadening), moderate stenosis (16-49\% diameter reduction defined as a systolic peak flow velocity $<1.25 \mathrm{~m} / \mathrm{s}$ and spectral broadening throughout systole) or severe stenosis ( $\geq 50 \%$ diameter reduction defined as a systolic peak flow velocity $>1.25 \mathrm{~m} / \mathrm{s}$, or occlusion corresponding with the absence of carotid arterial flow) [2527]. Finally, using the data from the most affected carotid branch, the participants were classified as having no or minimal CAS or any CAS (any CAS $>15 \%$ ). This last category consisted of subjects having only moderate CAS (16-49\% stenosis) or any severe CAS (50-100\% stenosis).

A reproducibility study of this non-invasive test was performed on a random sample $(n=41)$, the second measurement being performed 4 to 11 months after the first registration. The agreement between the first and the repeated classification was expressed as kappa value. The weighted kappa value was 0.41 , indicating a fair to moderate agreement [28].

Parameters of glycaemic and insulin levels. Fasting and 2-h post-load venous plasma glucose levels were determined with a glucose dehydrogenase method (Merck, Darmstadt, Germany) in the laboratory of the Academic Hospital of the Vrije Universiteit in Amsterdam. In diabetic subjects treated with oral hypoglycaemic agents or insulin, fasting plasma glucose and fasting serum insulin (in duplicate) were measured on one occasion only.

Fasting and 2-h post-load specific serum insulin levels were quantified (in duplicate) with an insulin-specific double-antibody radioimmunoassay (antibody: Linco SP21, St. Louis, Mo., USA). No cross-reactivity with proinsulin or split proinsulin was found. The intra-assay and inter-assay coefficients of variation for insulin were $5-8 \%$ and $7-11 \%$, respectively. 
Glycated haemoglobin $\left(\mathrm{HbA}_{1 \mathrm{c}}\right)$ was determined once by ion-exchange high-performance liquid chromatography, using a Modular Diabetes Monitoring System (Bio-Rad, Veenendaal, the Netherlands: normal range 4.3-6.1\%). Serum fructosamine concentrations were measured once, using a second generation serum fructosamine assay (Roche Diagnostica, Basle, Switzerland). The inter-assay coefficient of variation in the normal range was $4.6 \%$; in the pathological range $3.0 \%$.

Subjects treated with oral hypoglycaemic agents or insulin were classified as having known diabetes mellitus (KDM). All non-KDM subjects, including previously diagnosed diabetic patients with dietary advice only, were classified according to the WHO criteria [24] applied to mean fasting and mean 2-h post-load plasma glucose values of two OGTTs. In 25 subjects, at least one glucose value was missing at the second OGTT. These missing values were substituted by values from the first OGTT. Thus, in addition to the KDM category, the following three glucose tolerance categories were discerned: normal glucose tolerance (NGT), impaired glucose tolerance (IGT), and newly diagnosed diabetes mellitus (NDM).

Potential confounding factors. Concentrations of serum lipids were determined in the fasting blood samples of all subjects at the first OGTT. Total cholesterol, HDL-cholesterol (after precipitation of the low and very low-density lipoproteins [29]) and triglycerides were measured by enzymatic techniques (Boehringer-Mannheim, Mannheim, Germany). The Friedewald formula was used to calculate the LDL-cholesterol [30]. This formula was not applied to subjects with serum triglyceride levels over $8.0 \mathrm{mmol} / \mathrm{l}(\mathrm{n}=3)$. As the inclusion of subjects with triglyceride levels between 4.5 and $8.0 \mathrm{mmol} / \mathrm{l}(\mathrm{n}=20)$ barely influenced the studied associations, they were not excluded from further analyses.

Systolic and diastolic (Korotkov V) blood pressure was determined before the start of both OGTTs on the right arm of seated subjects, after at least 5 min resting, using a randomzero sphygmomanometer (Hawksley-Gelman Ltd., Lancing, Sussex, UK). The average of duplicate measurements on these two occasions was used for analysis. Hypertension was defined as present treatment with antihypertensive drugs or having an elevated blood pressure (diastolic $>95 \mathrm{mmHg}$ or systolic > $160 \mathrm{mmHg}$ ).

Height, weight and body circumferences were measured on all subjects, barefoot and wearing light clothes only, at the end of the first visit. Body mass index (BMI) was calculated as weight $(\mathrm{kg})$ divided by height squared $\left(\mathrm{m}^{2}\right)$. Waist/hip-ratio (WHR) was defined as waist circumference divided by hip circumference.

The medical history was obtained by means of a self-administered questionnaire. The subjects were asked whether they had received any specialist medical care during the past 10 years and, if so, for what reason and from which specialism. The history of macrovascular disease (myocardial infarction, angina pectoris, intermittent claudication, stroke, brain haemorrhage or transient palsy) was assessed by using a Dutch translation of the questionnaire from the London School of Hygiene and Tropical Medicine [31], which was also used in the Zutphen Study [32]. The general practitioners of those subjects reporting any macrovascular disease were asked to verify the indicated symptoms. Stroke or TIA was defined as a selfreported history of stroke or brain haemorrhage, or as permanent or transient palsy confirmed either by the general practitioner or by the use of platelet aggregation inhibitors without a history of cardiovascular disease. Information on family history of vascular disease was obtained by asking the participants whether any of their grandparents, parents, brothers or sisters had experienced any of the above-mentioned diseases before the age of 60 years. Smoking was expressed on a dichotomized scale (ever vs never smoked cigarettes, cigars or pipe) and on a continuous scale (cigarette pack-years). On their first visit to the study centre, the participants brought with them any medication they were currently using and the completed questionnaire. The answers on the questionnaire were checked for completeness and consistency, and the names of the medication and the dosages prescribed were registered.

\section{Statistical analysis}

The differences in characteristics between subjects in various glucose tolerance categories were assessed by using the oneway analysis of variance for the continuous parameters, and the chi-squared test for proportions. If the expected frequencies were less than 5, the Fisher's exact test was used. Because the distribution of the serum insulin levels was skewed, the Mann-Whitney test was used to evaluate differences in insulin levels between various glucose tolerance categories. In further analyses, insulin data were logarithmically transformed. The chi-square test for trend was used to investigate linear trends of the prevalence of CAS over the NGT, IGT and NDM categories.

To assess the population-based prevalence, the frequency of CAS was determined in 12 strata of the phase 3 cohort (age: 50-59, 60-69 and 70-74-years old; glucose tolerance category of the first OGTT: NGT, IGT, NDM and KDM). The prevalence of CAS in the original population-based sample $(n=2484)$ was estimated from the contributions of each age and glucose tolerance category stratum, based on the results of the first OGTT. Weighted stratum-specific variances were used to compute $95 \%$ confidence intervals (95\% CI).

At first, a univariate logistic regression analysis was performed with the glucose tolerance category as independent, and any severe CAS as the dependent variable. Seven multivariate logistic regression analyses, each correcting for the influence of age, sex, BMI, WHR, smoking behaviour, hypertension, triglycerides, LDL and HDL-cholesterol, and family history of cardio or cerebrovascular disease, were performed to assess the contribution of each of the five glycaemic indices (glucose tolerance category, fasting and 2-h post-load plasma glucose, $\mathrm{HbA}_{1 \mathrm{c}}$, and serum fructosamine), and the fasting and 2-h post-load specific insulin levels to the prevalence of CAS. Because no OGTT was performed on diabetic subjects treated with oral hypoglycaemic drugs or insulin, these subjects were not included in the analyses using the 2-h post-load plasma glucose and insulin levels. In all analyses, a p-value of less than 0.05 was regarded as statistically significant.

\section{Results}

Study population. As reported previously, the response-rate for phase 3 was $89 \%$ (631 of 708) [20]. Reasons for non-response were refusal to participate $(n=57)$, inability to visit the study centre before the end of the study $(n=15)$, moving out of Hoorn $(n=2)$, language problems $(n=2)$ and hospitalization $(\mathrm{n}=1)$.

In the non-participant group of phase 3, the percentage of female subjects was significantly higher, whereas age, hypertension, self-reported cerebrovascular symptoms (stroke, brain haemorrhage, or either 
Table 1. Characteristics of the study population stratified for glucose tolerance in phase 3 of the Hoorn Study

\begin{tabular}{|c|c|c|c|c|}
\hline Glucose tolerance & $\begin{array}{l}\text { Normal glucose } \\
\text { tolerance } \\
(n=287)\end{array}$ & $\begin{array}{l}\text { Impaired glucose } \\
\text { tolerance } \\
(\mathrm{n}=169)\end{array}$ & $\begin{array}{l}\text { Newly diagnosed } \\
\text { diabetes } \\
(\mathrm{n}=106)\end{array}$ & $\begin{array}{l}\text { Known diabetes } \\
(n=66)\end{array}$ \\
\hline \multicolumn{5}{|l|}{ D emographic data } \\
\hline Sex (\% male) & 52 & 47 & 46 & 39 \\
\hline \multicolumn{5}{|l|}{ Parameters of glucose metabolism } \\
\hline Fasting glucose (mmol/l) & $5.4 \pm 0.5$ & $6.1 \pm 0.7^{b}$ & $8.4 \pm 3.1^{\mathrm{b}}$ & $11.0 \pm 3.7^{\mathrm{b}}$ \\
\hline Serum fructosamine $(\mu \mathrm{mol} / \mathrm{l})$ & $240 \pm 17$ & $246 \pm 19$ & $286 \pm 69^{\mathrm{b}}$ & $335 \pm 66^{\mathrm{b}}$ \\
\hline \multirow[t]{2}{*}{ Fasting insulin $(\mathrm{pmol} / \mathrm{l})$} & 73 & $90^{\mathrm{b}}$ & $112^{\mathrm{b}}$ & $103^{\mathrm{b}}$ \\
\hline & $(52,99)$ & $(61,147)$ & $(74,163)$ & $(73,148)$ \\
\hline \multirow[t]{2}{*}{ 2-h post-load insulin (pmol/l) } & 303 & $607^{\mathrm{b}}$ & $508^{\mathrm{b}}$ & - \\
\hline & $(159,462)$ & $(351,1193)$ & $(242,956)$ & \\
\hline \multicolumn{5}{|l|}{ Confounding risk factors } \\
\hline \multirow[t]{2}{*}{ Smoking ${ }^{\mathrm{a}}$ (pack-years) } & 26.2 & 22.0 & 24.0 & 27.4 \\
\hline & $(9.6,41.6)$ & $(9.8,42.4)$ & $(10.8,45.9)$ & $(17.0,44.4)$ \\
\hline Waist/hip-ratio & $0.90 \pm 0.08$ & $0.93 \pm 0.08^{\mathrm{b}}$ & $0.96 \pm 0.09^{b}$ & $0.94 \pm 0.08^{\mathrm{b}}$ \\
\hline Body mass index $\left(\mathrm{kg} / \mathrm{m}^{2}\right)$ & $26.0 \pm 3.3$ & $27.7 \pm 3.7^{\mathrm{b}}$ & $28.6 \pm 4.1^{\mathrm{b}}$ & $29.1 \pm 5.2^{\mathrm{b}}$ \\
\hline LDL-cholesterol (mmol/l) & $4.61 \pm 1.03$ & $4.63 \pm 1.02$ & $4.26 \pm 1.16^{\mathrm{b}}$ & $4.26 \pm 1.01$ \\
\hline HDL-cholesterol (mmol/l) & $1.38 \pm 0.39$ & $1.23 \pm 0.34^{\mathrm{b}}$ & $1.13 \pm 0.27^{b}$ & $1.17 \pm 0.27^{\mathrm{b}}$ \\
\hline Triglycerides $(\mathrm{mmol} / \mathrm{l})$ & $1.49 \pm 0.74$ & $1.97 \pm 1.10^{\mathrm{b}}$ & $2.50 \pm 1.98^{b}$ & $2.31 \pm 1.45^{\mathrm{b}}$ \\
\hline Hypertension (\%) & 24.4 & $45.6^{\mathrm{b}}$ & $52.8^{\mathrm{b}}$ & $59.1^{\mathrm{b}}$ \\
\hline antihypertensive drugs (\%) & 17.1 & $33.1^{\mathrm{b}}$ & $35.8^{\mathrm{b}}$ & $51.5^{\mathrm{b}}$ \\
\hline \multicolumn{5}{|l|}{ Blood pressure $(\mathrm{mm} \mathrm{Hg})$} \\
\hline diastolic & $81 \pm 10$ & $85 \pm 10^{\mathrm{b}}$ & $84 \pm 9^{b}$ & $81 \pm 12$ \\
\hline systolic & $133 \pm 18$ & $144 \pm 20^{b}$ & $145 \pm 17^{b}$ & $143 \pm 21^{b}$ \\
\hline \multicolumn{5}{|l|}{ Family history of: } \\
\hline
\end{tabular}

Values are mean $\pm \mathrm{SD}$, percentage or median (20th, 80th percentile).

${ }^{a}$ Never smokers are excluded.

b $\mathrm{P}$-value $<0.05$ vs normal glucose tolerance

permanent or transient palsy), myocardial infarction, angina pectoris and intermittent claudication did not differ significantly between participants and non-participants. The absence of differences in prevalence rates of hypertension and cardiovascular disease suggests that the non-response was not associated with the presence of macrovascular disease. For technical reasons, the non-invasive assessment of three participants was not possible.

Characteristics of participants. Based on the mean fasting and 2-h post-load plasma glucose levels of two OGTTs and the WHO criteria, the study cohort was divided into three glucose tolerance categories: NGT $(n=287)$, IGT $(n=169)$ and NDM $(n=106)$, apart from KDM $(n=66$, of whom 52 were treated with oral hypoglycaemic agents and 14 with insulin).

Glycaemic indices, insulin levels, and other putative determinants of CAS are listed in Table 1. Some of these characteristics have been reported before [20]. As expected, glycaemic indices increased stepwise from NGT via IGT and NDM to KDM.
The fasting serum insulin level in the KDM group was non-significantly lower than in the NDM group $(p=0.52)$, whereas the 2-h post-load insulin level in NDM subjects was lower than in IGT subjects $(p=0.02)$. Because the distribution of the serum insulin levels and amount of smoking were skewed, values are represented as median $\left(20^{\text {th }}, 80^{\text {th }}\right.$ percentile).

The percentage of never smoked was highest in KDM subjects, but they had the highest mean cigarette consumption (pack-years). WHR, BMI, HDLcholesterol, triglycerides and systolic blood pressure were less favourable in the IGT, NDM and KDM categories than in the NGT. The percentage of hypertensive subjects increased over the respective glucose tolerance categories.

Prevalence of CA S in relation to glucose tolerance category. The crude prevalences of any CAS ( $>15 \%$ stenosis in any carotid branch), only moderate CAS (16-49\% stenosis) and any severe CAS ( $\geq 50 \%$ stenosis in any carotid branch) are shown in Table 2. 
Table 2. Prevalence of carotid artery stenosis according to glucose tolerance category

\begin{tabular}{|c|c|c|c|c|c|c|c|c|c|}
\hline \multirow{2}{*}{$\begin{array}{l}\text { Category of } \\
\text { carotid artery- } \\
\text { stenosis }\end{array}$} & \multicolumn{2}{|c|}{$\begin{array}{l}\text { Normal glucose } \\
\text { tolerance }(n=287)\end{array}$} & \multicolumn{2}{|c|}{$\begin{array}{l}\text { Impaired glucose } \\
\text { tolerance }(n=169)\end{array}$} & \multicolumn{2}{|c|}{$\begin{array}{l}\text { Newly diagnosed } \\
\text { diabetes }(n=106)\end{array}$} & \multicolumn{2}{|c|}{$\begin{array}{l}\text { Known diabetes } \\
(n=66)\end{array}$} & \multirow[b]{2}{*}{$p$-value ${ }^{a}$} \\
\hline & $\%$ & (n) & $\%$ & (n) & $\%$ & (n) & $\%$ & $(n)$ & \\
\hline Any & 0.7 & (2) & 1.8 & (3) & 1.9 & (2) & 7.6 & (5) & 0.27 \\
\hline Moderate & 0.3 & (1) & 0.6 & (1) & 1.9 & (2) & 7.6 & (5) & 0.14 \\
\hline Severe & 0.3 & (1) & 1.2 & (2) & 0.0 & (0) & 0.0 & (0) & 0.98 \\
\hline Moderate & 5.6 & (16) & 6.5 & (11) & 7.5 & (8) & 10.8 & (7) & 0.41 \\
\hline Severe & 2.1 & (6) & 3.0 & (5) & 5.7 & (6) & 6.2 & (4) & 0.08 \\
\hline \multicolumn{10}{|c|}{ External carotid artery } \\
\hline Any & 2.1 & (6) & 6.5 & (11) & 9.4 & $(10)$ & 9.1 & (6) & 0.001 \\
\hline Moderate & 1.7 & (5) & 4.7 & (8) & 4.7 & (5) & 4.5 & (3) & 0.06 \\
\hline Severe & 0.3 & (1) & 1.8 & (3) & 4.7 & (5) & 4.5 & (3) & $<0.005$ \\
\hline
\end{tabular}

$\%$, Percentage of subjects with CAS per glucose tolerance camoderate CAS, stenosis $16-49 \%$; tegory;

(n), number of subjects with CAS per stratum;

any CAS, stenosis $>15 \%$ : sum of prevalences of moderate CAS (stenosis $16-49 \%$ ) plus severe CAS (stenosis $\geq 50 \%$ );

severe CAS, stenosis $\geq 50 \%$;

a $\mathrm{P}$-values of chi-square tests for trend over normal glucose tolerance, impaired glucose tolerance and newly detected diabetes

Table 3. Calculated population-based age-specific prevalences of carotid artery stenosis in Hoorn, the Netherlands, 19891992

\begin{tabular}{|c|c|c|c|c|}
\hline \multirow{2}{*}{$\begin{array}{l}\text { Age- } \\
\text { category } \\
\text { (years) }\end{array}$} & \multicolumn{2}{|c|}{$\begin{array}{l}\text { Any carotid artery } \\
\text { stenosis }(>15 \%)\end{array}$} & \multicolumn{2}{|c|}{$\begin{array}{l}\text { Any severe carotid artery } \\
\text { stenosis }(\geq 50 \%)\end{array}$} \\
\hline & $\%$ & $95 \% \mathrm{Cl}$ & $\%$ & $95 \% \mathrm{Cl}$ \\
\hline $50-59$ & $6.1 \%$ & $2.1-10.1 \%$ & $1.8 \%$ & $0.0-4.1 \%$ \\
\hline $60-69$ & $8.3 \%$ & $4.2-12.5 \%$ & $2.6 \%$ & $0.8-4.4 \%$ \\
\hline $70-74$ & $18.8 \%$ & $11.7-25.9 \%$ & $7.3 \%$ & $2.6-12.0 \%$ \\
\hline All a & & & & \\
\hline $50-7$ & $9.0 \%$ & $6.3-11.7 \%$ & $3.0 \%$ & $1.5-4.5 \%$ \\
\hline
\end{tabular}

The prevalence of any CAS increased gradually from $9.4 \%$ in NGT subjects to $19.7 \%$ in KDM subjects. The prevalence of only moderate CAS was similar in NGT, IGT and NDM subjects $(6.6 \%, 7.1 \%$ and $5.7 \%$, respectively) and was $12.1 \%$ in the KDM category. The crude prevalence of any severe CAS increased stepwise from $2.8 \%$ in NGT, via $4.7 \%$ in IGT to $9.4 \%$ and $7.6 \%$ in NDM and KDM, respectively. The chi-square test for trend over the NGT, IGT and NDM categories was highly significant for any severe CAS $(p<0.01)$. The same holds for any severe external CAS $(p<0.005)$. The prevalence of any severe CAS was significantly higher in NDM than in NGT $(p<0.01)$, whereas the difference between KDM and NGT was borderline significant $(p=0.07)$. No significant differences were found between IGT and NGT $(p=0.41)$, IGT and NDM $(p=0.20)$, IGT and KDM $(p=0.59)$, and, NDM and KDM $(p=0.89)$.

The prevalence of stroke or TIA (confirmed self-reported cerebrovascular disease) was $1.7 \%$, $1.8 \%, 2.8 \%$ and $1.5 \%$, in the respective glucose tolerance categories (chi-square test for trend; $\mathrm{p}=0.79$ ).

Prevalence of CAS in a general Dutch Caucasian population. Table 3 shows the calculated age-specific prevalence rates of any CAS and any severe CAS in a general Dutch Caucasian population in the town of Hoorn. Because some contributing strata are small, $95 \%$ confidence intervals (95\% CI) are wide. The calculated population-based prevalences $(95 \%$ $\mathrm{CI}$ ) in 50-74-year-old subjects of any CAS and any severe CAS are $9.0 \%(6.3-11.7 \%)$ and $3.0 \%(1.5-$ $4.5 \%)$, respectively. The prevalences of both any CAS and any severe CAS were significantly higher in the 70-74-year-old subjects than in the $50-59$ or 60-69-year-old subjects. No significant differences were found between 50-59 and 60-69-year-old subjects.

D eterminants of any severe CA S. At first, logistic regression analyses were performed using four dichotomous dependent variables: a) only moderate CAS vs no or minimal CAS, b) any severe CAS vs no or minimal CAS, c) any severe CAS vs a combination of no or minimal CAS and only moderate CAS and, d) any CAS vs no or minimal CAS.

Cardiovascular risk factors were weakly and nonsignificantly associated with only moderate CAS (16-49\% stenosis) contrasted with no or minimal 
Table 4. Odds ratios for any severe carotid artery stenosis ${ }^{\mathrm{a}}$ of various parameters of glucose tolerance

\begin{tabular}{|c|c|c|c|}
\hline $\begin{array}{l}\text { Parameter of glucose } \\
\text { metabolism }\end{array}$ & $\begin{array}{l}\text { Odds } \\
\text { ratio }^{\mathrm{b}}\end{array}$ & $\begin{array}{l}95 \% \text { Confi- } \\
\text { dence interval }\end{array}$ & $p$-value \\
\hline \multicolumn{4}{|l|}{ D egree of glucose tolerance } \\
\hline Impaired vs normal & 1.30 & $0.45-3.79$ & 0.63 \\
\hline New diabetes vs normal & 2.73 & $0.89-8.33$ & 0.08 \\
\hline Known diabetes vs normal & 2.09 & $0.57-7.68$ & 0.27 \\
\hline $\begin{array}{l}\text { New }+ \text { known diabetes vs } \\
\text { normal }\end{array}$ & 2.48 & $0.88-7.01$ & 0.09 \\
\hline $\begin{array}{l}\text { Fasting plasma glucose } \\
\text { per } \mathrm{mmol} / \mathrm{l}\end{array}$ & 1.10 & $0.97-1.25$ & 0.13 \\
\hline $\begin{array}{l}\text { 2-h plasma glucose } \\
\text { per } \mathrm{mmol} / 1\end{array}$ & 1.09 & $1.01-1.18$ & 0.03 \\
\hline $\begin{array}{l}\mathrm{HbA}_{1 \mathrm{c}}^{\mathrm{c}} \\
\text { per \% }\end{array}$ & 1.29 & $1.02-1.63$ & 0.03 \\
\hline $\begin{array}{l}\text { Serum fructosamine } \\
\quad \text { per } 10 \mu \mathrm{mol} / 1\end{array}$ & 1.06 & $1.00-1.13$ & 0.07 \\
\hline Fasting specific insulin ${ }^{c}$ & & & \\
\hline $\begin{array}{l}\text { per } 100 \mathrm{pmol} / 1 \\
\text { per } \ln \text { unit }\end{array}$ & $\begin{array}{l}1.01 \\
1.03\end{array}$ & $\begin{array}{l}0.44-2.30 \\
0.39-2.75\end{array}$ & $\begin{array}{l}0.98 \\
0.95\end{array}$ \\
\hline 2-h specific insulin ${ }^{d}$ & & & \\
\hline per $100 \mathrm{pmol} / \mathrm{l}$ & 0.98 & $0.89-1.08$ & 0.63 \\
\hline per ln unit & 0.84 & $0.47-1.50$ & 0.55 \\
\hline
\end{tabular}

${ }^{\text {a }}$ Haemodynamic stenosis $\geq 50 \%$ (systolic peak flow velocity $>1.25 \mathrm{~m} / \mathrm{s}$ or no arterial flow detectable);

${ }^{\mathrm{b}}$ Multivariate logistic regression analyses; each model consisted of the parameter of glucose metabolism at issue and the following possibly confounding cardiovascular risk factors: age, sex, smoking behaviour, W/H-ratio, BMI, LDL-cholesterol, HDL-cholesterol, triglycerides, hypertension and family history of cardio- or cerebrovascular disease;

${ }^{\mathrm{c}}$ Diabetic subjects treated with oral hypoglycaemic agents or insulin included;

${ }^{\mathrm{d}}$ Diabetic subjects treated with oral hypoglycaemic agents or insulin excluded

CAS (0-15\% stenosis) as reference category. However, the same risk factors were significantly associated with any severe CAS ( $\geq 50 \%$ stenosis) compared to no or minimal CAS (0-15\% stenosis). Similar associations were found contrasting any severe CAS ( $\geq 50 \%$ stenosis) with a combination of no or minimal CAS and only moderate CAS ( $<50 \%$ stenosis) as reference category. If any CAS (only moderate CAS or any severe CAS; $>15 \%$ stenosis) was contrasted with no or minimal CAS $(0-15 \%$ stenosis $)$, the odds ratios of the various cardiovascular risk factors decreased, but remained significant. Therefore, we decided to perform logistic regression analyses with the indicator variable any severe CAS (present vs absent) as the dependent variable.

Firstly, the odds ratios for IGT, NDM or KDM vs NGT were calculated to estimate the relative risk for any severe CAS in the respective glucose tolerance categories. In the univariate logistic regression analysis, NDM subjects had a significantly higher risk for any severe CAS than NGT subjects (odds ratio (OR): $3.63 ; p=0.0001$ ), whereas this was not found for either IGT (OR: 1.73; $\mathrm{p}=0.28$ ) or KDM (OR: $2.86 ; p=0.07)$ subjects. Combining the NDM and KDM subjects into one diabetes category, the OR was $3.33(p=0.01)$. In the multivariate analyses, the ORs of NDM and diabetic subjects for any severe CAS decreased and were no longer statistically significant (2.73; $p=0.08$ and 2.48; $p=0.09$, respectively). No increased risk could be demonstrated for IGT or KDM subjects compared to NGT subjects in the multivariate analysis.

In the multivariate analyses any severe CAS was significantly associated with $\mathrm{HbA}_{1 \mathrm{c}}$ (OR: 1.29 per\% increase; $p=0.03$ ) and borderline significantly associated with serum fructosamine (OR: 1.06 per $10 \mu \mathrm{mol} / \mathrm{l} ; \mathrm{p}=0.07)$, whereas no significant association with fasting plasma glucose was found (OR: 1.10 per $\mathrm{mmol} / \mathrm{l} ; \mathrm{p}=0.13$ ). After exclusion of the subjects treated with oral hypoglycaemic agents or insulin, these associations were no longer significant (data not shown). However, in the same sub-group, the 2-h post-load plasma glucose level was significantly associated with any severe CAS (OR: 1.09 per $\mathrm{mmol} / \mathrm{l} ; \mathrm{p}=0.03$ ).

No univariate or multivariate associations could be shown between either fasting or 2-h post-load specific insulin and CAS. Even after exclusion of KDM subjects, no associations were found.

The best fitting multivariate logistic regression model, including $\mathrm{HbA}_{1 \mathrm{c}}$ as the parameter of glycaemic level, revealed that among the cardiovascular risk indicators only age (OR: 1.10; 95\% CI: $1.03-$ 1.17 per year older), HDL-cholesterol (OR: 0.78; $95 \%$ CI: $0.66-0.93$ per $0.1 \mathrm{mmol} / \mathrm{l}$ increase), and BMI (OR: 0.89; $95 \%$ CI: 0.78-1.00 per $\mathrm{kg} / \mathrm{m}^{2}$ ) contributed significantly to the risk for any severe CAS. Remarkably, smoking behaviour (OR: 1.30; $95 \%$ CI: 0.46-3.67 ever vs never smoked), hypertension (OR: 1.92; 95\% CI: $0.86-4.29$ present vs absent), triglycerides (OR: 0.98; $95 \%$ CI: $0.65-1.48$ per $\mathrm{mmol} / \mathrm{l}$ ), and LDL-cholesterol (OR: 1.12; 95\% CI: 0.78-1.62 per $\mathrm{mmol} / \mathrm{l})$ were not significantly associated with any severe CAS.

In KDM subjects $(n=66)$, no significant associations were found between $\mathrm{HbA}_{1 \mathrm{c}}$ (OR: 1.71; $95 \%$ CI: $0.93-3.13$ per \%), fasting plasma glucose (OR: 1.04; $95 \%$ CI: $0.82-1.33$ per $\mathrm{mmol} / \mathrm{l}$ ), serum fructosamine (OR: 2.85; 95\% CI: 0.63-12.93 per $100 \mu \mathrm{mol} / \mathrm{l}$ ) or fasting specific insulin (OR: 0.79; 95\% CI: $0.19-3.39$ per $100 \mathrm{pmol} / \mathrm{l}$ ) and any severe CAS in univariate logistic regression analyses. HDLcholesterol (OR: 0.62; 95\% CI: 0.40-0.97 per $0.1 \mathrm{mmol} / \mathrm{l}$ ) and diastolic blood pressure (OR: 0.90; 95\% CI: $0.82-0.99$ per $\mathrm{mmHg}$ ) were significantly associated with any severe CAS in univariate analyses, whereas all other cardiovascular risk indicators were not. The small number of treated diabetic subjects prevented multivariate analyses within the KDM group. 


\section{Discussion}

Prevalence data concerning non-invasively diagnosed CAS in various glucose tolerance categories are sparse. To our knowledge, this is the first populationbased survey to determine the prevalence of CAS in NGT, IGT, NDM and KDM subjects in one cohort. One previous study reported a prevalence of $7.9 \%$ [18] of any severe CAS in NIDDM subjects treated with sulphonylurea or insulin, which is similar to our results $(7.6 \%)$. In recently diagnosed NIDDM subjects a prevalence of $4.4 \%$ (95\% CI: $1.2-11.3 \%$ ) for any severe CAS was reported [19]. This is about half the prevalence in Hoorn $(9.4 \%)$, which may partly be explained by the younger age (35-75 years), possibly a better glycaemic control (median fasting blood glucose $7.7 \mathrm{mmol} / \mathrm{l}$ ) and the small number of subjects $(n=68)$ in the latter study. Our data show that the prevalence of non-invasively diagnosed only moderate CAS is similar in NGT, IGT and NDM subjects and seems to be increased in KDM subjects only. The prevalence of any severe CAS in any carotid branch increased with an increasing glycaemic level. This also holds for any severe CAS in both the internal and the external carotid artery. In NDM subjects, the prevalence was significantly higher than in NGT subjects, in both the internal and the external carotid artery. No significant difference in the prevalence of CAS was found between KDM and IGT on the one hand, and NGT subjects on the other. These findings were confirmed by univariate logistic regression analysis. Multiple logistic regression analysis confirmed that NDM subjects had a 2-3 fold increased risk for any severe CAS. The strength of the association is similar to the previously reported $2-4$ fold increased risk for cerebrovascular morbidity and mortality among NDM subjects [1-4]. Our data differ from the results of a Japanese study in which significantly higher intima media thicknesses were shown in mildly hyperglycaemic and IGT subjects [33]. According to the WHO criteria we included mildly hyperglycaemic subjects in the NGT group, which may have resulted in a loss of contrast between our IGT and NGT subjects. The small number of subjects with any severe CAS $(n=31)$ may also explain why the association between IGT or KDM and any severe CAS did not reach statistical significance.

The Hoorn Study data show a population-based prevalence of any severe CAS of 3.0\% in the 50-74year-old cohort. A clearly higher prevalence is seen in the subjects over 70 years of age. Estimates of the prevalence of severe CAS vary across studies from only $1.4 \%$ in the Rotterdam Study to $8 \%$ in the Framingham study [10-17]. This variance may partly be explained by the differences in the methods of assessing stenosis (e.g. duplex, continuous wave or percentage diameter reduction in B-mode image), in definition of severe CAS ( $>40 \%, \geq 50 \%$ or $>75 \%$ ), in age, and in non-response. Because of the small numbers, sex differences could not be tested.

In logistic regression analyses, $\mathrm{HbA}_{1 \mathrm{c}}$, 2-h postload glucose and serum fructosamine (borderline) turned out to be risk factors for any severe CAS, even after correction for other cardiovascular risk factors. These associations between continuous parameters of glycaemia and duplex Doppler diagnosed CAS have not been described before. Using intima media thickness as parameter of carotid atherosclerosis, this association was also reported by O'Leary et al. [34] and Shahar et al. [35], but contradicted by Markussis [36]. NIDDM has been reported to be independently associated with CAS in many studies $[4$, $10,12,35,37-39]$.

In our data, age and HDL-cholesterol levels are the most important determinants of any severe CAS, which is in agreement with the findings in other carotid atherosclerosis studies [12, 39]. Triglyceride and LDL-cholesterol levels were not associated with CAS, which might, at least partly, be explained by the cross-sectional study design. Selective mortality may also be involved. Furthermore, LDL-cholesterol is reported to become a less important cardiovascular risk factor in elderly subjects $[12,40]$. The lack of association between triglycerides and CAS may also be influenced by the imprecision of measurement of the triglycerides. Conflicting results are reported concerning the role of serum lipids as cardiovascular risk factors [39]. The negative association between BMI and any severe CAS is also reported for peripheral arterial disease $[20,41,42]$. One explanation might be the selective mortality of obese persons with CAS, resulting in a disappearance, or, even a reversal of the association between BMI and CAS. Another explanation might be the unfavourable risk profile of elderly subjects losing weight. The small number of KDM subjects $(n=66)$ did not allow an extensive analysis of determinants of CAS in this sub-group. No significant association between smoking behaviour and CAS could be shown. Remarkably, a negative association between diastolic blood pressure and CAS was found. A J-shaped association between diastolic blood pressure and the intimal media thickness has recently been reported in elderly Caucasian subjects [43]. In subjects with a diastolic blood pressure less than $60 \mathrm{mmHg}$ an increased thickness was found. This finding may be explained by stiffening of the carotid artery wall due to generalised atherosclerosis. Furthermore, medial arterial calcification may be involved in diabetic subjects.

Serum insulin is reported to be an independent risk factor for the development of coronary heart disease [44-46]. Population-based studies evaluating the role of specific insulin as a risk factor for non-invasively diagnosed CAS are rare. Various studies using intima media thickness as parameters of carotid atherosclerosis reported conflicting results regarding 
the associations with insulin levels [34, 36, 47]. In the present study, neither fasting nor 2-h post-load specific insulin levels were associated with any severe CAS in univariate and multivariate analyses. Exclusion of the diabetic subjects treated with oral hypoglycaemic agents or insulin did not alter the relationship (data not shown). The same association has previously been reported for insulin and peripheral arterial disease $[20,48]$. One reason may be the large inter-individual variability of insulin levels, which may be explained by two concurrent phenomena, affecting the insulin levels in opposite directions in diabetic subjects: peripheral insulin resistance and deficient insulin production in the pancreas. Another explanation may be that the deleterious effects of insulin resistance and/or deficiency are mediated by resulting metabolic disturbances, such as hyperglycaemia or dyslipidaemia, and are not caused by the direct effects of (pro)insulin [22, 49].

The final conclusion is that, after correction for cardiovascular risk factors, glycated haemoglobin, 2-h post-load plasma glucose and serum fructosamine (borderline) are independent determinants of any severe CAS, whereas specific insulin is not. As these data result from a cross-sectional survey, longitudinal studies are needed to further explore these associations, their underlying mechanisms and their clinical consequences.

A cknowledgements. We gratefully acknowledge the skilfull technical assistance of Ms. M. Bischoff and Ms. J. Scholma who were responsible for all vascular laboratory tests.

\section{References}

1. Pyörälä K, Laakso M, Uusitupa M (1987) Diabetes and atherosclerosis: an epidemiologic view. Diabetes Metab Rev 3: 463-524

2. Donahue RP, Orchard TJ (1992) Diabetes mellitus and macrovascular complications. An epidemiological perspective. Diabetes Care 15: 1141-1155

3. Stout RW (1992) Diabetes mellitus and atherosclerosis. In: Stout RW (ed) Diabetes and atherosclerosis. Developments in cardiovascular medicine, Vol 125. Kluwer Academic Publishers, Dordrecht, Boston, London pp 53-87

4. Bell DSH (1994) Stroke in the diabetic patient. Diabetes Care 17: 214-219

5. Jungquist G, Nilsson B, Ostberg H et al. (1989) Carotid artery blood flow velocity related to transient ischemic attack and stroke in a population study of 69-year-old men. Stroke 20: $1327-1330$

6. Admani AK, Mangion DM, Naik DR (1991) Extracranial carotid artery stenosis: prevalence and associated risk factors in elderly stroke patients. Atherosclerosis 86: 31-37

7. Autret A, Saudeau D, Bertrand P, Pourcelot L, Marchal C, De Boisvilliers S (1987) Stroke risk in patients with carotid stenosis. Lancet I:888-890

8. Bogousslavski J, Van Melle G, Despland PA, Regli F (1990) Alcohol consumption and carotid atherosclerosis in the Lausanne Stroke Registry. Stroke 21: 715-720
9. Perez-Burkhardt JL, Gonzalez-Fajardo JA, Rodriguez E, Mateo AM (1994) Amaurosis fugax as a symptom of carotid artery stenosis. Its relationship with ulcerated plaque. J Cardiovasc Surg 53: 15-18

10. Roederer GO, Langlois YE, Jager KA et al. (1984) The natural history of carotid arterial disease in asymptomatic patients with cervical bruits. Stroke 15: 605-613

11. Ramsey DE, Miles RD, Lambeth A, Sumner DS (1987) Prevalence of extracranial carotid artery disease: a survey of an asymptomatic population with non-invasive techniques. J Vasc Surg 5: 584-588

12. Willeit J, Kiechl S (1993) Prevalence and risk factors of asymptomatic extracranial carotid artery atherosclerosis. A population-based study. Arterioscler Thromb 13: 661668

13. Josse MO, Toubol PJ, Mas JL et al. (1987) Prevalence of asymptomatic carotid artery stenosis. Neuroepidemiol 6: 150-152

14. Colgan MP, Strode GR, Sommer JD et al. (1988) Prevalence of asymptomatic internal carotid disease: Results from duplex scanning in 348 unselected volunteers. J Vasc Surg 8: 674-678

15. Jungquist G, Hanson BS, Isacson SO et al. (1991) Risk factors for carotid artery stenosis: An epidemiological study of men aged 69 years. J Clin Epidemiol 44: 347-353

16. Fowl RJ, Marsch JG, Love M et al. (1991) Prevalence of haemodynamically significant stenosis of the carotid artery in an asymptomatic population. Surg Gyn Obst 172: 13-16

17. Bots ML, Breslau PJ, Briet E et al. (1992) Cardiovascular determinants of carotid artery disease. The Rotterdam Study. Hypertension 19: 717-720

18. Chan A, Beach KW, Martin DC, Strandness DE (1983) Carotid artery disease in NIDDM diabetes. Diabetes Care 6: 562-569

19. Standl E, Stiegler H (1993) Microalbuminuria in a random cohort of recently diagnosed type 2 (non-insulin-dependent) diabetic patients living in the Greater Munich Area. Diabetologia 36: 1017-1020

20. Beks PJ, Mackaay AJC, Neeling JND de, Vries H de, Bouter LM, Heine RJ (1995) Peripheral arterial disease in relation to glycaemic level in an elderly Caucasian population: the Hoorn Study. Diabetologia 38: 86-96

21. Mooy JM, Grootenhuis PA, De Vries H, Heine RJ, Bouter LM (1992) The Hoorn Study: disorders of glucose tolerance in a general Caucasian population. Neth $\mathbf{J}$ Internal Med 41:A29 (Abstract)

22. Grootenhuis PA (1994) Epidemiological aspects of the insulin resistance syndrome. [Thesis], Vrije Universiteit, Amsterdam

23. De Neeling JND (1994) Peripheral nerve function in relation to glucose tolerance. [Thesis], Vrije Universiteit, Amsterdam

24. World Health Organization Study Group on Diabetes Mellitus (1985) Technical report series No 727, WHO, Geneva

25. Roederer RG, Langlois YE, Chan AW et al. (1982) Ultrasonic duplex scanning of extracranial carotid arteries: improved accuracy using new features from the common carotid artery. J Cardiovasc Ultrasonography 1: 373-379

26. Hartnell GG, Gibson RN, Williams R, Hemingway AP (1990) Carotid artery stenosis - reassessment of the Doppler criteria. Eur J Radiol 10: 147-153

27. Faught WE, Mattos MA, Bemmelen PS van et al. (1994) Color-flow duplex scanning of carotid arteries: new velocity criteria based on receiver operator characteristic analysis for threshold stenoses used in the symptomatic and asymptomatic carotid trials. J Vasc Surg 19: 818-828 
28. Brennan P, Silman A (1992) Statistical methods for assessing observer variability in clinical measures. BMJ 304: 1491-1494

29. Grove TH (1979) Effect of high-density lipoprotein cholesterol by precipitation with sodium phosphotungstate-magnesium. Clin Chem 24: 560-564

30. Friedewald WT, Levy RI, Fredrickson DS (1972) Estimation of the concentration of low-density lipoprotein cholesterol in plasma, without use of the preparative ultracentrifuge. Clin Chem 18: 499-502

31. Rose GA, Blackburn H (1968) Cardiovascular survey methods. WHO Monograph Series No 56 WHO, Geneva

32. Feskens EJM, Kromhout D (1989) Cardiovascular risk factors and the 25-year incidence of diabetes mellitus in middle-aged men. The Zutphen Study. Am J Epidemiol 130: 1101-1108

33. Yamasaki Y, Kawamori R, Matsushima H et al. (1995) Asymptomatic hyperglycaemia is associated with increased intimal plus medial thickness of the cartotid artery. Diabetologia 38: 585-591

34. O'Leary DH, Polak JF, Kronmal RA et al. (1992) Distribution and correlates of sonographically detected carotid artery disease in the Cardiovascular Health Study. Stroke 23: 1752-1760

35. Shahar E, Vitelli LL, Heiss G et al. (1995) Glycosylated hemoglobin level in diabetes-free individuals and carotid intimal-medial thickening: the atherosclerosis risk in communities (ARIC) study. Circulation 91: 932 (Abstract)

36. Markussis V, Beshyah SA, Fisher C et al. (1992) Detection of premature atherosclerosis by high-resolution ultrasonography in symptom-free hypopituitary adults. Lancet II:1188-1192

37. Kawamori R, Yamasaki Y, Matsushima H et al. (1992) Prevalence of carotid atherosclerosis in diabetic patients. Diabetes Care 15: 1290-1294

38. Tell GS, Howard G, McKinney WM (1989) Risk factors for site specific extracranial carotid artery plaque distribution as measured by B-mode ultrasound. J Clin Epidemiol 42: 551-559

39. Bots ML (1993) Wall thickness of the carotid artery as an indicator of generalized atherosclerosis. [Thesis], Erasmus Universiteit, Rotterdam
40. Pooling Project Research Group (1978) Relationship of blood pressure, serum cholesterol, smoking habit, relative weight and ECG abnormalities to incidence of major coronary events: Final report of Pooling Project. J Chron Dis 31: 201-306

41. Walters DP, Gatling W, Mullee MA, Hill RD (1992) The prevalence, detection, and epidemiological correlates of peripheral vascular disease: a comparison of diabetic and non-diabetic subjects in an English community. Diabet Med 9: 710-715

42. Fowkes FGR, Housley E, Riemersma RA et al. (1992) Smoking, lipids, glucose intolerance, and blood pressure as risk factors for peripheral atherosclerosis compared with ischemic heart disease in the Edinburgh Artery Study. Am J Epidemiol 135: 331-340

43. Bots ML, Witteman JCM, Hofman A, Jong PTVM de, Grobbee DE (1996) Low diastolic blood pressure and atherosclerosis in elderly subjects. The Rotterdam study. Arch Intern Med 156: 843-848

44. Pyörälä K, Savolainen E, Kaukola S, Haapakoski J (1985) Plasma insulin as coronary heart disease risk factor: relationship to other risk factors and predictive value during $9 \frac{1}{2}$ year follow-up of the Helsinki Policemen Study population. Acta Med Scand [Suppl] 701: 38-52

45. Fontbonne A, Tchobroutsky G, Eschwege E, Richards JL, Claude JR, Rosselin GE (1988) Coronary heart disease mortality risk: plasma insulin level is a more sensitive marker than hypertension or abnormal glucose tolerance in overweight males: the Paris prospective study. Int J Obesity 12: $557-565$

46. Mykkänen L, Laakso M, Pyörälä K (1993) High plasma insulin level associated with coronary artery disease in the elderly. Am J Epidemiol 137: 1190-1202

47. Folsom AR, Eckfeldt JH, Weitzman et al. (1994) Relation of carotid artery wall thickness to diabetes mellitus, fasting glucose and insulin, body size, and physical activity. Stroke 25: 66-73

48. Stolk RP (1995) Insulin resistance in the elderly. The Rotterdam Study. [Thesis], Erasmus Universiteit, Rotterdam

49. Haffner SM, Mykkänen L, Stern MP, Valdez RA, Heisserman JA, Bowsher RR (1993) Relationship of proinsulin and insulin to cardiovascular risk factors in nondiabetic subjects. Diabetes 42: 1297-1302 